\title{
Sciences
}

Vol. 06, No. 03, pp. 127-143, September 2013

\section{VIBRATION AND KINEMATIC ANALYSIS OF SCARA ROBOT STRUCTURE}

\author{
Talib EH. Elaikh ${ }^{1}$, HaiderJ. Abed ${ }^{2}$, Kadhim M. Abed ${ }^{3}$, \\ Salah M. Swadi ${ }^{4}$, KadhimKarim $\mathbf{M}^{5}$ \\ ${ }^{1,2,3,5}$ College of engineering, Thi-Qar University; ${ }^{4}$ College of Engineering, Mustansiria \\ University
}

(Received: 18/10/2011; Accepted: 27/12/2012)

\begin{abstract}
This paper presents a procedure for assessing the vibration analysis of type SCARA robots. The motion and running conditions of such robots are very complicated that leads to produce vibration and shock which are generated by arm profile in running conditions. In this study the vibration analysis gives the feasibility of the preview control was examined to improve the performance of the SCARA robots system. As it is important for containment the robot arm trajectories generated by the model to show satisfactory safe performance under vibration occurrence phenomena so that they completely avoid errors, the results obtained from such vibration analysis assessment procedure are considered to be valuable and reliable process not only with respect to vibration risk assessment but also for predicting kinematic analysis by investigating the robot arm motion using the kinematic and vibration methods. Forced vibrations is studied analytically help the designer to predict the behavior and design the robot hardware or control system. Theoretical results show reduction in both vibration amplitude and time history response.
\end{abstract}

Keywords:-SCARA robot, vibration analysis, Modeling, Control Kinematic analysis.

\section{1- INTRODUCTION}

SCARA robot is one of the industrial robots which can replace humans in carrying out various types of operations. They can as well serve machine tools as to carry out various tasks like welding, handling, painting, assembling, automotive, electronics and other industries. SCARA robots have two rotational joints on a horizontal plane and usually one translational joint on the vertical axis. The structure of SCARA robots is simple and they are widely used all over the world because the structure is suitable for automation lines and other 
industrial purposes. SCARA robots are in particular utilized for pick-and-place task. In such cases, the motion of SCARA robots commonly is periodic.

The robot was developed in the laboratory of Professor Makino at Japan's Yamanashi University (Makino and Furuya) ${ }^{(1)}$. Various studies were devoted to this architecture. A dynamic modeling and linearization technique for a SCARA robot was presented by Tern et al. ${ }^{(2)}$. A new energy-saving method for SCARA robots was proposed by Guangqiang Lu et.al. (3). To effectively reduce energy consumption, nonlinear robot dynamics are mechanically liberalized in this paper. A complete mathematical model of SCARA robot including servo actuators dynamics with dynamic simulation was presented by Mahdi et. al (4). A simple method for estimating the dynamic parameters of SCARA robot has been presented by Yan Meng and S.P.Chen ${ }^{(5)}$. Residual vibrations of industrial SCARA robots in wafer handling applications were investigated by WeiMIN et. al. ${ }^{(6)}$. Philip Voglewede et. at. (7) were studied the dynamic performance of a SCARA robot manipulator with uncertainty using polynomial chaos theory. Dynamic calibration of SCARA robot was presented by M. Indri et. al. ${ }^{\left({ }^{8}\right)}$. Mathematical modeling, simulation and experimental verification of a SCARA robot were presented by Das, M.T. and L. C. Dulger ${ }^{(9)}$. Appropriate Mathematical Model of DC Servo Motors Applied in SCARA Robots was presented by Attila L. Bencsik ${ }^{(10)}$. A mathematical model for an industrial track robot was proposed by WeiMIN Tao et. al. ${ }^{(11)}$. A complete mathematical model of SCARA robot and the PD controller for each robot joint is presented by Das T. and Dülger C. ${ }^{(12)}$.

The Selective Compliant Articulated/Assembly Robot Arm (SCARA) as shown in figure (1) is usually a 4-axis industrial robot. The kinematics is like a human arm, with the first joint being referred to as the shoulder and the second as the elbow. These two joints allow movement in the $\mathrm{X}$ - and $\mathrm{Y}$ - axes. The third joint is a translation joint and moves along the Z-axis. The last joint, called Theta-Z, gives a rotation around the Z-axis (wrist rotation).

The first robot arm articulated on the robot console and swivel able about a first swivel axis as shown in figure (2), and second swivel arm articulated on the first swivel arm and swivel able around the second swivel axis extending substantially parallel to the first swivel axis, at least one work unit, at least one first swivel motor for swiveling an arm unit composed of the first and second robot arms relative to the robot console, at least one second swivel motor for turning the second robot arm relative to the first robot arm, and at least one work motor for actuating the work unit, with the motors being controllable by a power electronics, with electrical circuits including convertor circuits for current supply of the motors and at least one control circuit for operating the convertor circuits and thereby for 
controlling the motors, and with at least one rectifier circuit being received in at least one robot arm.

Vibration and kinematic analysis of SCARA robot are presented in this paper. In a kinematic analysis the position, velocity and acceleration of all links are calculated without considering the forces that cause this motion. The relationship between motion, and the associated forces and torques is studied in robot dynamics ${ }^{(13)}$. The kinematic separate in two types, direct kinematics and inverse kinematics. In forward kinematics, the length of each link and the angle of each joint is given and we have to calculate the position of any point in the work volume of the robot. In inverse kinematics, the length of each link and position of the point in the work volume is given and we have to calculate the angle of each joint. Vibration analysis of this model using Lagrange's approach was made to obtain frequency equation the dynamic stiffness method applies mainly to excitations of harmonic nodal forces. For vibrational loading, modal analysis is generally required. This study analyzes the effects of vibration loading on the dynamic stability of a force-controlled flexible manipulator. The forced vibration analysis is then carried out to obtain the eigenvalues and eigenvectors. The modal approach for applied loading leads to the formulation of a model used to predict the behavior of the SCARA robot. The aim of using MATLAB-Simulink-Sim Mechanics is to build the model and to analyze the kinematic equation. The results of kinematic and vibration analysis using MATLAB/Simulink software are presented.

\section{2- KINEMATIC ANALYSIS:}

The mathematical model of a two-joint type SCARA robot is illustrated ${ }^{(15)}$. For the mass centers of the robot links are concentrated at the centers of the arm. Hence, the two 1 inks have the same moments of inertia. Table (1) shows the parameters of the two-link rigid type robot. The geometry of SCARA robot is shown in Fig (3).

The positions, velocities, and acceleration of SCARA robot shown in Fig. (3), can be obtained by using the kinematic analysis and the aid of the Euler' identity as ${ }^{(16)}$ :

$\theta_{1}=2 \tan ^{-1}\left(\frac{-Q \pm \sqrt{\left(Q^{2}-4 * P * R\right)}}{2 * P}\right)$

$\theta_{2}=2 \tan ^{-1}\left(\frac{-T \pm \sqrt{\left(T^{2}-4 * S * U\right)}}{2 * S}\right)$

Where

$$
\begin{aligned}
& P=\frac{a^{2}-b^{2}+c^{2}+d^{2}}{2 a}+d, Q=-2 c, \text { and } R=\frac{a^{2}-b^{2}+c^{2}+d^{2}}{2 a}-d \\
& S=\frac{a^{2}-b^{2}-c^{2}-d^{2}}{2 b}+d, T=-2 c, \text { and } U=\frac{a^{2}-b^{2}-c^{2}-d^{2}}{2 b}-d
\end{aligned}
$$


The angular velocities of SCARA robot links are given by:

$\omega_{1}=\frac{\dot{c} \tan \theta_{2}+\dot{d}}{a\left(\cos \theta_{1} \tan \theta_{2}-\sin \theta_{1}\right)}$

$\omega_{2}=\frac{\dot{c} \tan \theta_{1}+\dot{d}}{b\left(\cos \theta_{2} \tan \theta_{1}-\sin \theta_{2}\right)}$

And the angular acceleration are:

$\alpha_{1}=\frac{a \omega_{1}^{2} \sin \theta_{1}-\left(a \omega_{1}^{2} \cos \theta_{1} \cot \theta_{2}+b \omega_{2}^{2} \cos \theta_{2} \cot \theta_{2}+\ddot{d} \cot \theta_{2}\right)+\ddot{c}+b \omega_{2}^{2} \sin \theta_{2}}{a\left(\cos \theta_{1}+\sin \theta_{1} \cot \theta_{2}\right)}$

$\alpha_{2}=\frac{a \alpha_{1} \sin \theta_{1}+a \omega_{1}^{2} \cos \theta_{1}+b \omega_{2}^{2} \cos \theta_{2}+\ddot{d}}{b \sin \theta_{2}}$

The translation accelerations of the links are:

$A_{1}=a j \alpha_{1} e^{j \theta_{1}}-a \omega_{1}^{2} e^{j \theta_{1}}$

$A_{2}=b j \alpha_{2} e^{j \theta_{2}}-b \omega_{2}^{2} e^{j \theta_{2}}$

$A_{3}=\ddot{c}$

$A_{4}=\ddot{d}$

\section{3- VIBRATION ANALYSIS}

The uncoupled equations of motion of a SCARA robot (as modeled in figure (4)), subjected to vibrational loading can be derived by menus of the Lagrange's equation approach as:

The kinetic energy of the robot can be written as:

$$
\mathrm{K} . \mathrm{E}=\frac{1}{2} \mathrm{~m}_{1}\left(\frac{1}{2} \mathrm{~L}_{1} \dot{\theta}_{1}\right)^{2}+\frac{1}{2} \mathrm{~m}_{1}\left(\mathrm{~L}_{1} \dot{\theta}_{1}\right)^{2}+\frac{1}{2} \mathrm{~m}_{2} \mathrm{v}_{2}^{2}+\frac{1}{2} \mathrm{~m}_{2}\left(\mathrm{~L}_{2} \dot{\theta}_{2}\right)^{2}
$$

Where, for small angle

$$
v_{2}^{2}=\left(L_{1} \dot{\theta}_{1}+\frac{1}{2} L_{2} \dot{\theta}_{2}\right)^{2}
$$

By substituting equation (14) in equation (13) \& rearranging yields;

$$
\mathrm{K} . \mathrm{E}=\frac{1}{2} \mathrm{~m}_{1}\left(\frac{1}{2} \mathrm{~L}_{1} \dot{\theta}_{1}\right)^{2}+\frac{1}{2} \mathrm{~m}_{1}\left(\mathrm{~L}_{1} \dot{\theta}_{1}\right)^{2}+\frac{1}{2} \mathrm{~m}_{2}\left(\mathrm{~L}_{1} \dot{\theta}_{1}+\frac{1}{2} \mathrm{~L}_{2} \dot{\theta}_{2}\right)^{2}+\frac{1}{2} \mathrm{~m}_{2}\left(\mathrm{~L}_{2} \dot{\theta}_{2}\right)^{2}
$$

The potential energy of the SCARA robot can be written as:

$$
\mathrm{P} . \mathrm{E}=\frac{1}{2} \mathrm{~m}_{1} \mathrm{gL}\left(1-\cos \theta_{1}\right)+\mathrm{m}_{2} \mathrm{~g}\left(\mathrm{~L}_{1}\left(1-\cos \theta_{1}\right)+\frac{1}{2} \mathrm{~L}_{2}\left(1-\cos \theta_{2}\right)\right)
$$


After differentiating the equation (15) first for $\dot{\theta}_{1}$ and then with respect to time we obtain:

$$
\frac{\mathrm{d}}{\mathrm{dt}}\left(\frac{\partial \mathrm{K} \cdot \mathrm{E}}{\partial \dot{\theta}_{1}}\right)=\left(\frac{5}{4} \mathrm{~m}_{1}+\mathrm{m}_{2}\right) \mathrm{L}_{1}^{2} \ddot{\theta}_{1}+\frac{1}{2} \mathrm{~m}_{2} \mathrm{~L}_{1} \mathrm{~L}_{2} \ddot{\theta}_{2}
$$

Differentiating the equation (16) with respect to $\theta_{1}$

$$
\frac{\partial \mathrm{P} . \mathrm{E}}{\partial \theta_{1}}=\frac{1}{2} \mathrm{~m}_{1} \mathrm{gL}_{1} \sin \theta_{1}+\mathrm{m}_{2} \mathrm{gL}_{1} \sin \theta_{1}
$$

And, for a small angle

$$
\begin{array}{rlrl}
\therefore & \frac{\partial \mathrm{P} \cdot \mathrm{E}}{\partial \theta_{1}}=\left(\frac{1}{2} \mathrm{~m}_{1}+\mathrm{m}_{2}\right) \mathrm{g} \mathrm{L}_{1} \theta_{1} \\
\frac{\partial K \cdot E}{\partial \theta_{1}}=0 \quad ; \frac{\partial D \cdot E}{\partial \dot{\theta}_{1}}=0 \quad ; Q_{1}=0
\end{array}
$$

After repeating the same procedure for kinetic and potential energies for $\theta_{2}$, we obtained

$$
\frac{\mathrm{d}}{\mathrm{dt}}\left(\frac{\partial \mathrm{K} . \mathrm{E}}{\partial \dot{\theta}_{2}}\right)=\frac{1}{2} \mathrm{~m}_{2} \mathrm{~L}_{1} \mathrm{~L}_{2} \ddot{\theta}_{1}+\frac{5}{4} \mathrm{~m}_{2} \mathrm{~L}_{2}^{2} \ddot{\theta}_{2}
$$

$\frac{\partial \mathrm{P} . \mathrm{E}}{\partial \theta_{2}}=\frac{1}{2} \mathrm{~m}_{2} \mathrm{gL}_{2} \theta_{2}$

$$
\frac{\partial K \cdot E}{\partial \theta_{2}}=0 \quad ; \frac{\partial D \cdot E}{\partial \dot{\theta}_{2}}=0 \quad ; Q_{2}=F_{\text {。 }}
$$

Lagrange's equation approach is:

$$
\frac{\mathrm{d}}{\mathrm{dt}}\left(\frac{\partial \mathrm{K} \cdot \mathrm{E}}{\partial \dot{\mathrm{q}}_{\mathrm{i}}}\right)-\frac{\partial \mathrm{K} \cdot \mathrm{E}}{\partial \mathrm{q}_{\mathrm{i}}}+\frac{\partial \mathrm{P} \cdot \mathrm{E}}{\partial \mathrm{q}_{\mathrm{i}}}+\frac{\partial \mathrm{D} \cdot \mathrm{E}}{\partial \dot{\mathrm{q}}_{\mathrm{i}}}=\mathrm{Q}_{\mathrm{i}}
$$

By substituting the equations $(17,19$, and 20) in Lagrange's equation yields

$$
\left(\frac{5}{4} \mathrm{~m}_{1}+\mathrm{m}_{2}\right) \mathrm{L}_{1}^{2} \ddot{\theta}_{1}+\frac{1}{2} \mathrm{~m}_{2} \mathrm{~L}_{1} \mathrm{~L}_{2} \ddot{\theta}+\left(\frac{1}{2} \mathrm{~m}_{1}+\mathrm{m}_{2}\right) \mathrm{gL}_{1} \theta_{1}=0
$$

And. by substituting the equations $(21,22$, and 23) in Lagrange's equation we obtain:

$$
\frac{1}{2} m_{2} L_{1} L_{2} \ddot{\theta}_{1}+\frac{5}{4} m_{2} L_{2}^{2} \ddot{\theta}_{2}+\frac{1}{2} m_{2} g L_{2} \theta_{2}=F_{\text {。 }}
$$


Now writing the equation of motion $(25,26)$ of the SCARA robot in matrix form:

$$
\left[\begin{array}{cc}
\left(\frac{5}{4} m_{1}+m_{2}\right) L_{1}^{2} & \frac{1}{2} m_{2} L_{1} L_{2} \\
\frac{m_{2}}{2} L_{1} L_{2} & \frac{5}{4} m_{2} L_{1}^{2}
\end{array}\right]\left\{\begin{array}{l}
\ddot{\theta}_{1} \\
\ddot{\theta}_{2}
\end{array}\right\}+\left[\begin{array}{cc}
\left(\frac{m_{1}}{2}+m_{2}\right) g L_{1} & 0 \\
0 & \frac{m_{2}}{2} g_{2}
\end{array}\right]\left\{\begin{array}{c}
\theta_{1} \\
\theta_{2}
\end{array}\right\}=\left\{\begin{array}{c}
0 \\
F_{0}
\end{array}\right\}
$$

\section{4- EIGEN VALUES \& EIGEN VECTORS}

Using the dynamic matrix procedure to determine the eigenvalues (natural frequencies) and eigenvectors (mode shapes) of the SCARA robot as:

$$
[\mathrm{M}]\{\ddot{\theta}\}+[\mathrm{K}]\{\theta\}=0
$$

Eigenvalues (natural frequencies)

$$
\because|[\mathrm{D}]-\lambda[\mathrm{I}]|=0
$$

Eigenvectors (mode shapes):

$$
[[\mathrm{D}]-\lambda[\mathrm{I}]] \phi_{\mathrm{ij}}=0
$$

Time response:

$$
\begin{aligned}
& \left\{\begin{array}{l}
\theta_{1} \\
\theta_{2}
\end{array}\right\}=\left\{\begin{array}{l}
A_{1} \\
A_{2}
\end{array}\right\} \sin (\omega t+\psi) \Rightarrow\left\{\begin{array}{c}
\ddot{\theta}_{1} \\
\ddot{\theta}_{2}
\end{array}\right\}=-\omega^{2}\left\{\begin{array}{l}
A_{1} \\
A_{2}
\end{array}\right\} \sin (\omega t+\psi) \\
& \left\{\begin{array}{c}
f_{O} \\
O
\end{array}\right\}=\left\{\begin{array}{c}
f_{O} \\
0
\end{array}\right\} \sin (\omega t+\psi)
\end{aligned}
$$

For generalized response for SCARA robot is:

$$
\begin{aligned}
& \mathrm{q}_{\mathrm{i}}(\mathrm{t})=\sum_{\mathrm{j}=1}^{\mathrm{n}} \mathrm{A}_{\mathrm{j}} \phi_{\mathrm{ij}} \sin \left(\omega_{\mathrm{j}} \mathrm{t}+\psi_{\mathrm{j}}\right) \\
& \mathrm{q}_{1}(\mathrm{t})=\mathrm{A}_{1} \phi_{11} \sin \left(\omega_{1} \mathrm{t}+\psi_{1}\right)+\mathrm{A}_{2} \phi_{12} \sin \left(\omega_{2} \mathrm{t}+\psi_{2}\right) \\
& \mathrm{q}_{2}(\mathrm{t})=\mathrm{A}_{1} \phi_{21} \sin \left(\omega_{1} \mathrm{t}+\psi_{1}\right)+\mathrm{A}_{2} \phi_{22} \sin \left(\omega_{2} \mathrm{t}+\psi_{2}\right)
\end{aligned}
$$

The phase angles $(\psi)$ can be determined from the four initial conditions of the SCARA robot:

Initial displacement:

$q_{1}(0)=0, \quad q_{2}(0)=0$

Initial velocities: 
$\dot{q}_{1}(0)=0, \dot{q}_{2}(0)=0$

By substituting the four initial conditions in equation's $(42,43)$, we can obtained the phase angle.

\section{5- RESULTS ANDDISCUSSION}

The end effector coordinates of the robotic arm ( $\mathrm{x}$ and $\mathrm{y}$ ) are located by using the forward kinematics and meshgrid command in MATLAB package by introducing the values of the positions $\theta_{1}$ and $\theta_{2}$ when the ranges of the angles $\theta_{1}$ and $\theta_{2}$ are $0 \leq \theta_{1} \leq 180^{\circ}$ and 0 $\leq \theta_{2} \leq 180^{\circ}$ respectively, as shown in Fig. (5).

In fig. (6),we can see the X-Y coordinates are generated for all $\theta_{1}$ and $\theta_{2}$ combination by using the forward kinematics for $0 \leq \theta_{1} \leq 360^{\circ}$ and $0 \leq \theta_{2} \leq 360^{\circ}$.

When using inverse kinematics analysis by introducing the above values of ( $\mathrm{x}$ and $\mathrm{y}$ ) to MATLAB program of the derived equations (1and 2), to get the same value of angles relative to forward kinematics as shown in figure (7). By using MATLAB-Simulink-Sim Mechanics to build the model and to analyze the kinematic equations, the same results for position, velocity, and acceleration of the SCARA robot were found comparison to the results which obtained when using derived equations, as shown in Figs. (9-11).

The frequency response of the SCARA robot is computed for a range of values of exciting frequencies. The exciting load is a constant force Fo applied at the free end for the second link as shown in Fig. (12).

\section{6- CONCLUSION}

Vibration and kinematics analysis of SCARA robot are presented in this paper. Also, the Simulation studies were performed by using MATLAB software. The main concluding remarks of the paper can be summarized as follows:

1- The model analysis of SCARA robot was performed. The natural frequencies and mode shapes were obtained for several parameters combination. Frequency response analysis was performed by finding the vibrational amplitudes and the accumulated deflections in the free end of the robot. 
2- Dynamic analysis to analyze SCARA robot subject to loads that vary with time or frequency where all links of the robot have resonant or natural frequencies, and if the structure is excited at, or close to one of these frequencies then a very high amplitude response can occur. Therefore, it is necessary to ensure in the design of the SCARA robot that the resonant and excitation frequencies are not close to each other.

3- The behavior of a structure to time-varying excitation is computed. Frequency response analysis computes the structural response to steady-state oscillatory excitation. In addition, it is also possible to conduct a random analysis with frequency response.

4- MATLAB/ Simulink, structure for SCARA robot are built which enables the researchers to investigate the robot parameters using both forward and inverse kinematics.

5- An agreement between the results for derived equation and the MATLAB software is certainly obtained herein.

\section{REFERENCES}

1- Makino, H., and Furuya, N. (1982). SCARA robot and its family. In Proceedings of the 3rd International Conference on Assembly Automation Boeblingen, Germany433444.

2- Tern, T. J., Bejeay, A. K., Lotdorl, A., and Chen, Y. Nonlinear feedback in robust link control. In Proceedings of the IEEE Control conference, New York, 1984, pp. 38-51 (IEEE, Piscataway, New Jersey.

3- Guangqiang Lu, Sadao Kawamura, and Mitunori Uemura” Proposal of an Energy Saving Control Method for SCARA Robots, Journal of Robotics and Mechatronics Vol. 24 No.1, 2012.

4- Mahdi S. Alshamasin, Florin Ionescu, Riad T. Al-Kasasbeh" Kinematic Modeling and Simulation of a SCARA Robot by Using Solid Dynamics and Verification by MATLAB/ Simulink, European Journal of Scientific Research, Vol.37 No.3 (2009), pp.388-405.

5- Yan Meng and S. P. Chan "Parameters Identification for SCARA Robot” The Fourth International Conference on Control, Automation, Robotics and Vision, Singapore, 36 December, 1996.

6- WeiMin TAO, MingJun ZHANG, Ou MA and XiaoPing YUN" Residual Vibration Analysis and Suppression for SCARA Robots in Semiconductor Manufacturing" 
International Journalof Intelligent Controland Systems, VOL. 11, NO. 2, JUNE 2006, 97-105.

7- Philip Voglewede, Anton H. C. Smith, and Antonello Monti” Dynamic Performance of a SCARA Robot Manipulator With Uncertainty Using Polynomial Chaos Theory IEEE Transactions on Robotics, VOL. 25, NO. 1, February 2009.

8- M. Indri. G. Calafiore. G. Legnani. F. Jatta .A. Visioli” Optimized Dynamic Calibrationofa SCARARobot, 15th Triennial World Congress, Barcelona, Spain 200.

9- Attila L. Bencsik (2004) "Appropriate Mathematical Model of DC Servo Motors Applied in SCARA Robots” Acta Polytechnica Hungarica, Vol. 1, No. 2, 2004.

10- WeiMin Tao, MingJun Zhang, Ou Ma "Modeling and Vibration Suppression for Industrial Track Robots" Proceedings of the 2006 IEEE International Conference on Robotics and Automation Orlando, Florida - May 2006.

11- T. Das, C. Dülger "Mathematical modeling, simulation and experimental verification of a SCARA robot” Simulation Modeling Practice and Theory 13 (2005) 257-271. 1985; 15(1):116-32.

12- Robot Kinematics, Wikipedia Web Site. http://www.wikipedia.com

13- Burton, T.D. Introduction to Dynamic Systems Analysis, McGraw-Hill, Inc., 1994.

14- K. Sahari, K. H. Weng, Y. W. Han, A. Anuar, M. Z. Baharuddin and S. S. K. Mohideen" Design And Development Of A 4-Dof Scara Robot For Educational Purposes, Journal Technology, Vol. 54, 2011, pp. 193-215.

15- Haider J. Abed "Kinematic analysis of bicycle pedaling" Thi- Qar university journal for engineering science, Vol. 1, No.2, December, 2010.

16- Wu, J.S., Chou, H.M., 1999. A new approach for determining the natural frequencies and mode shapes of a uniform beam carrying any number of sprung masses. Journal of Sound and Vibration 220, 451-468.

17- D. Luenberger. Introduction to dynamic systems theory, models, and applications. John Wiley and Sons, New York Chichester Brisbane Toronto, 1979.

18-C. Ross. Differential Equations An Introduction with Mathematica. Springer-Verlag, New York Berlin Heidelberg.

\section{NOMENCLATURE:}


$[\mathrm{K}] \quad$ Stiffness matrix, $[\mathrm{N} / \mathrm{m}]$

[M] Mass matrix, $[\mathrm{kg}]$

[D] Dynamical Matrix

[I] Identity Matrix

$\mathrm{Q}_{1}, \mathrm{Q}_{2} \quad$ External Force $[\mathrm{N}]$

$\mathrm{L}_{\mathrm{i}} \quad$ Robot link length, $[\mathrm{mm}],(\mathrm{i}=1,2)$

$m 1, m 2 \quad$ masses of Robot links1 and 2 respectively [kg]

g Gravity $\left[\mathrm{m} / \mathrm{s}^{2}\right]$

$\mathrm{F}_{\mathrm{o}}$ Excitation force $[\mathrm{N}]$

$\omega_{1}, \omega_{2}$ Angular velocities of links1 and 2 respectively ( $\left.\mathrm{rad} / \mathrm{sec}\right)$.

$\boldsymbol{A}_{\mathbf{3}}, \boldsymbol{A}_{\mathbf{4}}$ Translation accelerations of links 3 and 4 respectively $\left(\mathrm{m} / \mathrm{sec}^{2}\right)$.

$\dot{\boldsymbol{c}}, \dot{\boldsymbol{d}}$ Linear velocities of links3 and 4 respectively $(\mathrm{m} / \mathrm{sec})$.

$\boldsymbol{\alpha}_{\mathbf{1}}, \boldsymbol{\alpha}_{\mathbf{2}}$ Angular accelerations of links 1 and 2 respectively ( $\left.\mathrm{rad} / \mathrm{sec}^{2}\right)$.

a Length of link $1(\mathrm{~m})$.

b Length of link $2(\mathrm{~m})$.

c Length of link 3 (it represents y component of robot's tip) (m).

d Length of link 4 (it represents x component of robot's tip) (m).

$\theta_{\mathrm{i}} \quad$ Angle of links (degree), $(\mathrm{i}=1,2,3,4)$.

Table (1): Parameters of the two-link rigid -type robot.

\begin{tabular}{|c|c|c|c|}
\hline Link & Mass(kg) & Length (m) & $\begin{array}{l}\text { Tensor of Moment of inertia }\left(\mathrm{kg}^{*} \mathrm{~m}^{2}\right) \\
\qquad[\mathrm{x} \mathrm{y} \mathrm{z}]\end{array}$ \\
\hline 1 & 1 & 1 & {$\left[\begin{array}{lllllllll}0.083 & 0 & 0 ; 0 & 0 & 0 ; & 0 & 0 & 0.083\end{array}\right]$} \\
\hline 2 & 1 & 1 & {$\left[\begin{array}{lllllllll}0.083 & 0 & 0 ; 0 & 0 & 0 ; & 0 & 0 & 0.083\end{array}\right]$} \\
\hline
\end{tabular}




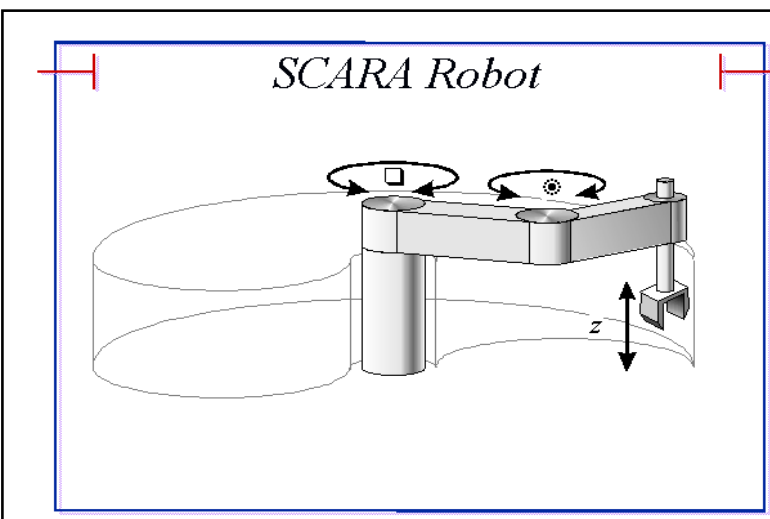

Figure (1): SCARA Robot ${ }^{(14)}$.

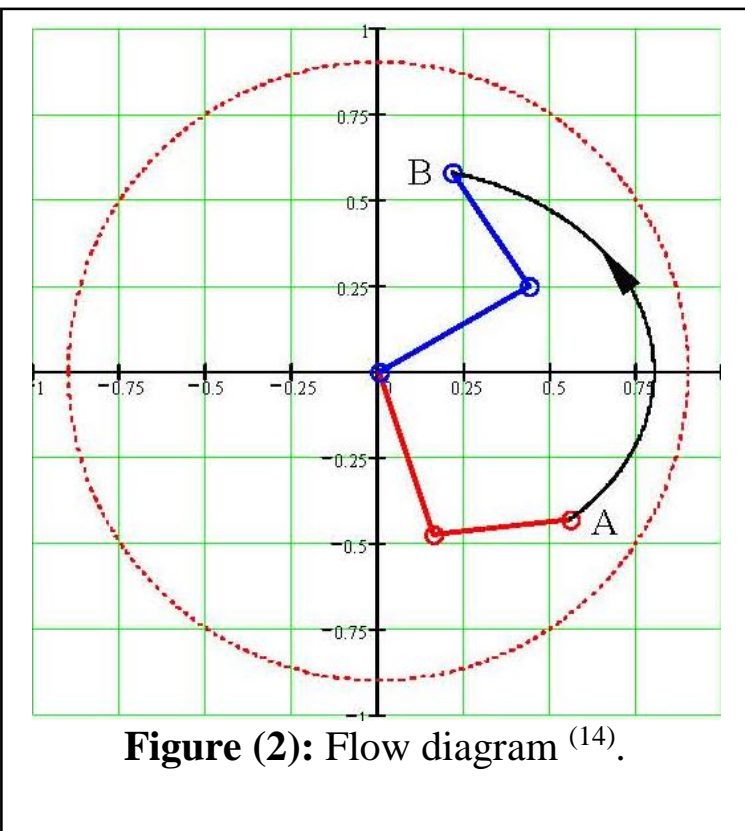




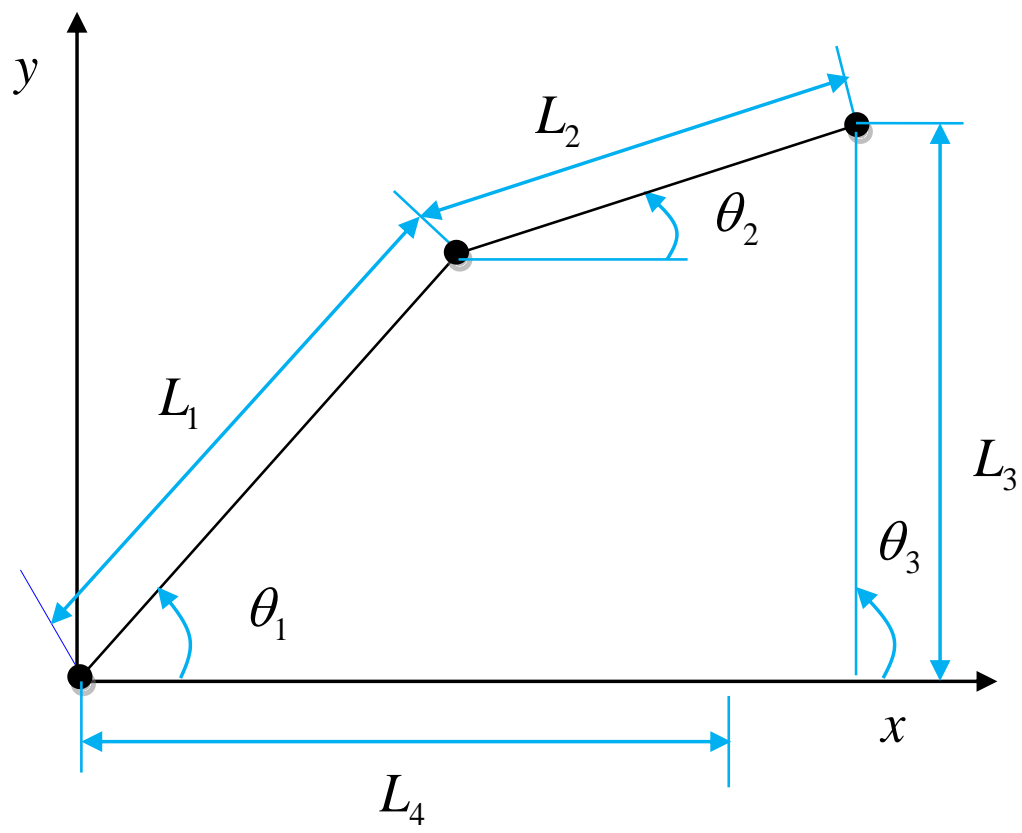

Figure (3): Geometry of SCARA robot.

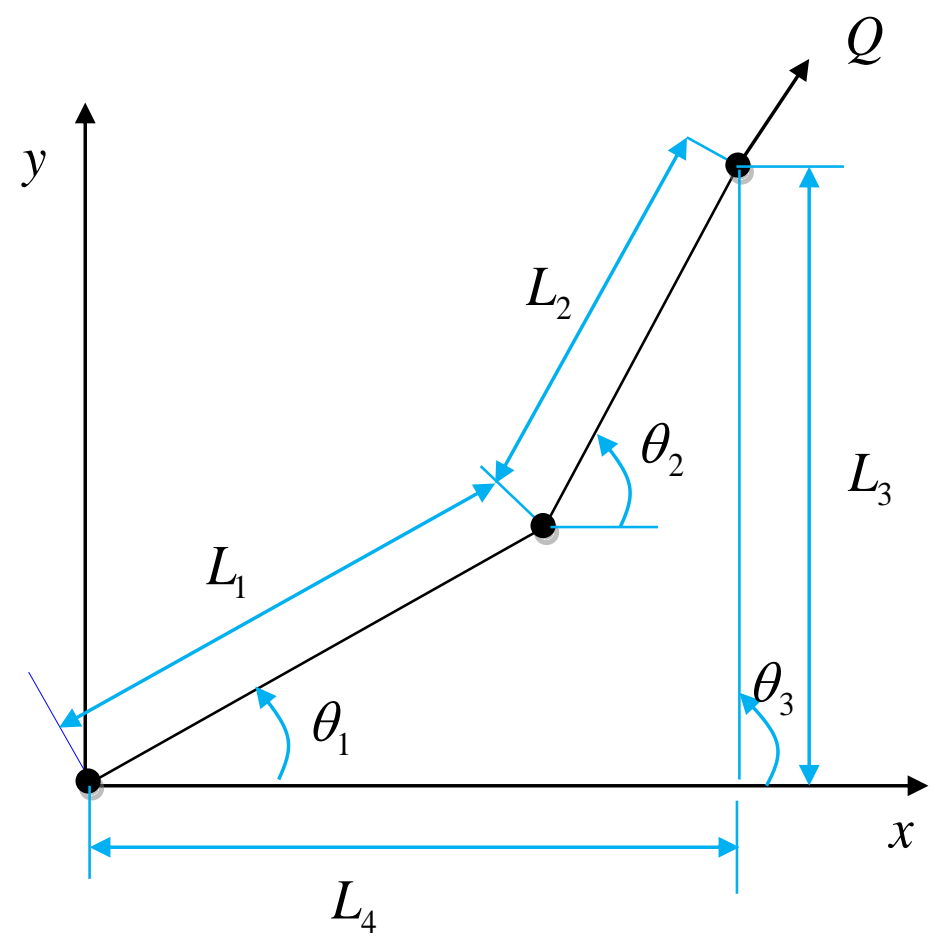

Figure (4): Vibrational modeling of SCARA robot. 


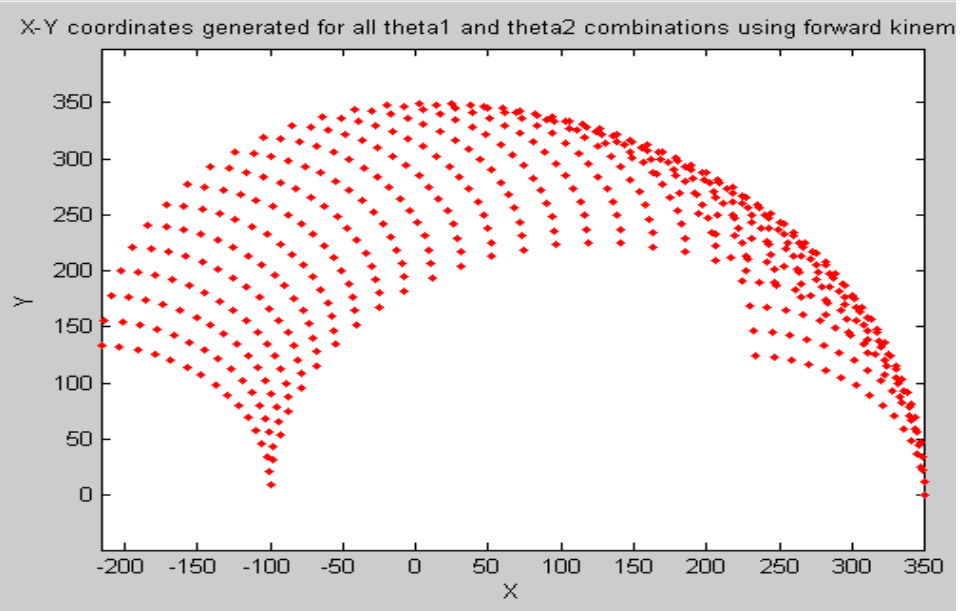

Figure (5): X-Y generated for all $\theta_{1}$ and $\theta_{2}$ combinations using forward kinematics (where $0 \leq \theta_{1} \leq 90^{\circ}$ and

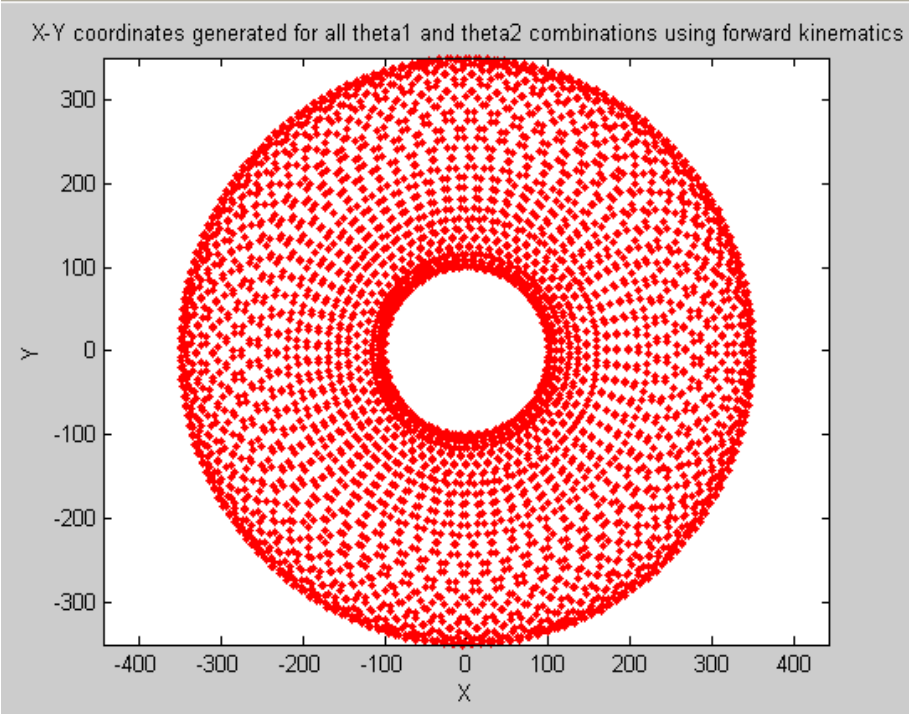

Figure (6): $\mathrm{X}-\mathrm{Y}$ generated for all $\boldsymbol{\theta}_{1}$ and $\theta_{2}$ combinations using forward kinematics (where $0 \leq \theta_{1} \leq 360^{\circ}$ and $0 \leq \theta_{2} \leq 360^{\circ}$

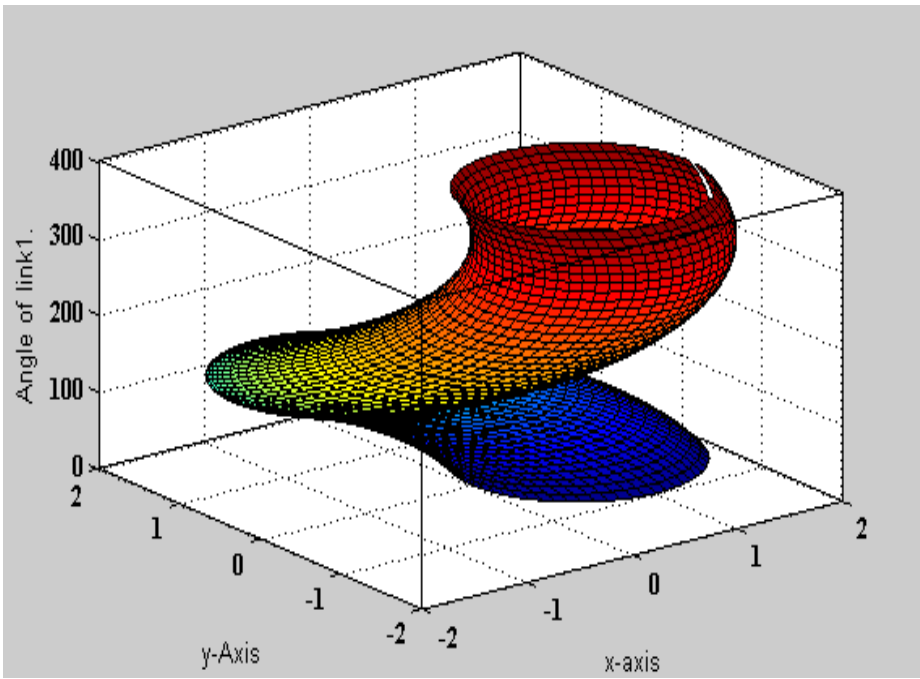

Figure (7): Angle of link1 by forward and inverse 


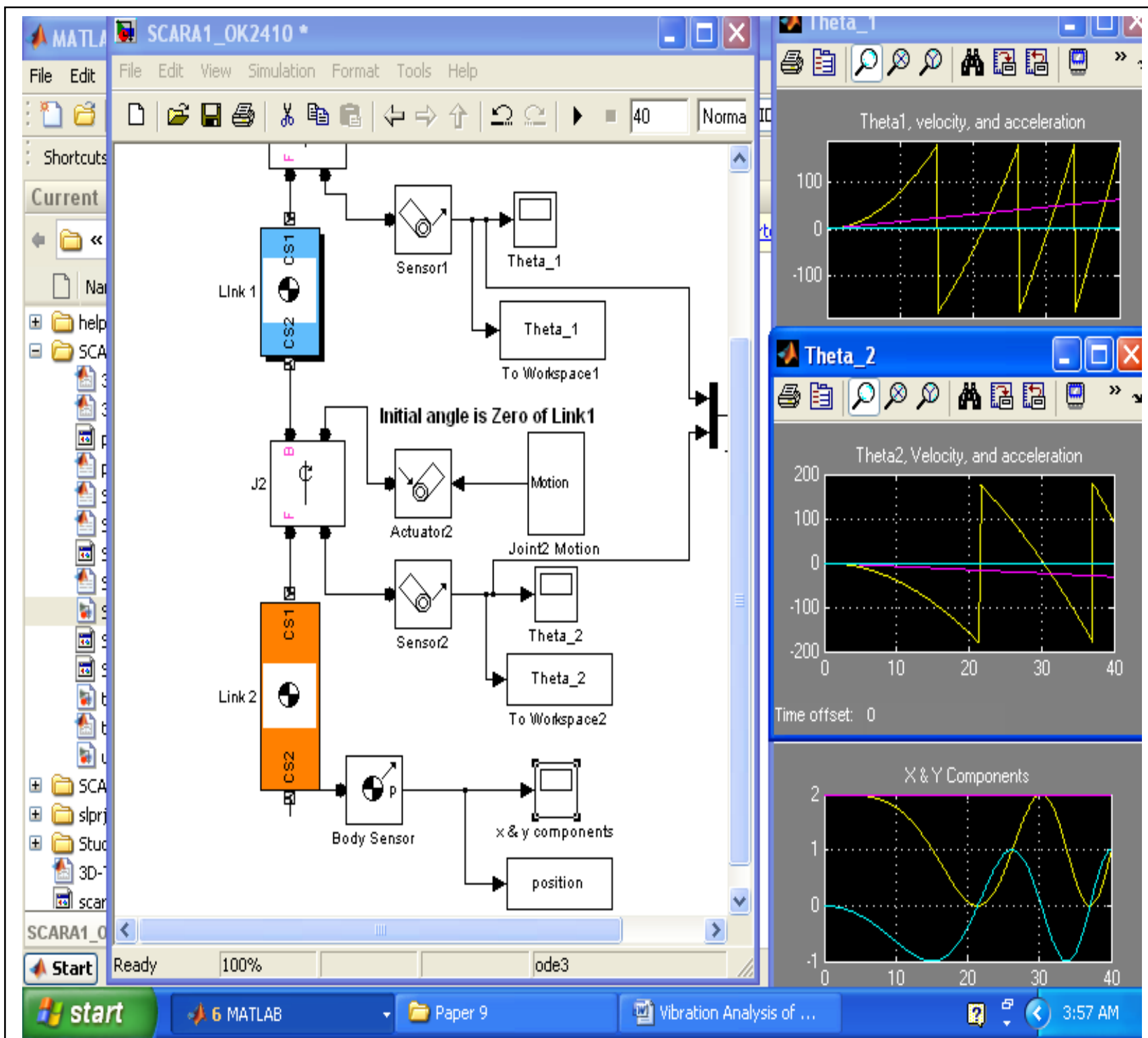

Figure (8): SCARA robot simulation in MATLAB/ Simulink/ Sim-mechanics. 


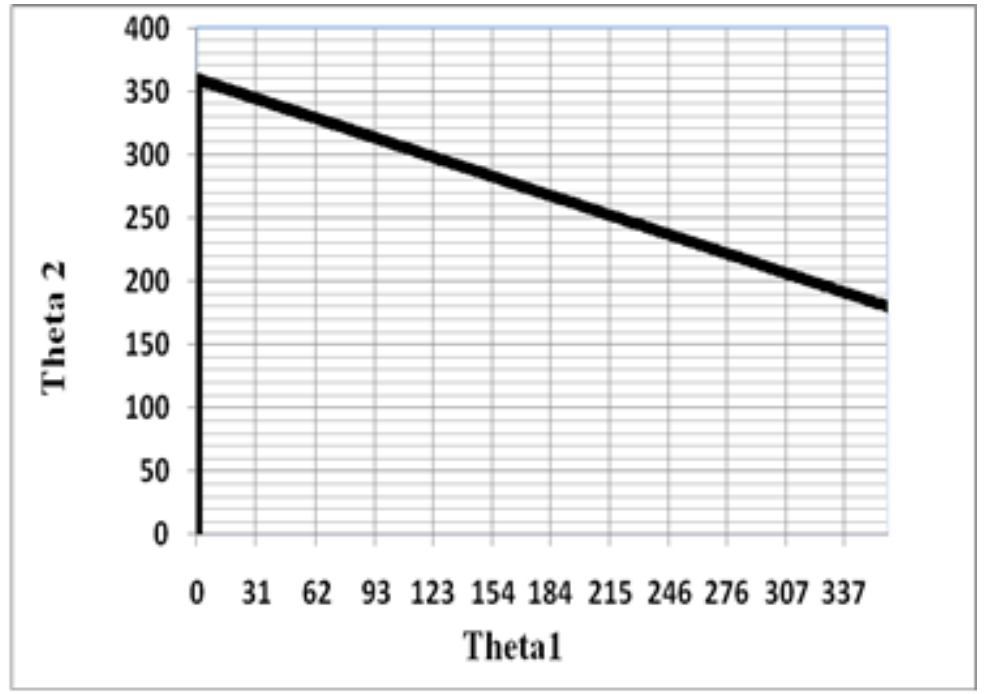

Figure (9): Theta2 versus Theta1 for derived equations and Simulink model.

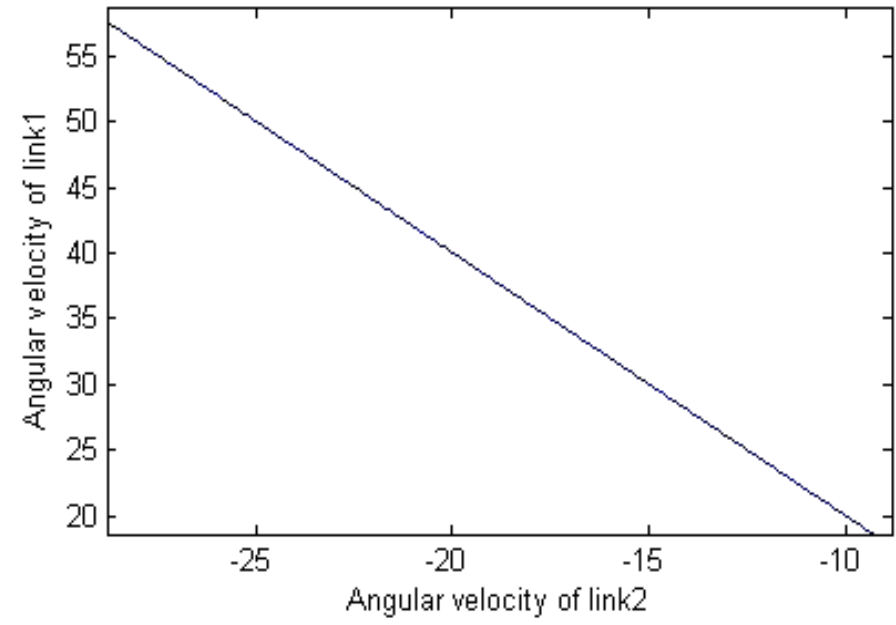

Figure (10): Angular velocities by derived equations and Simulink model.

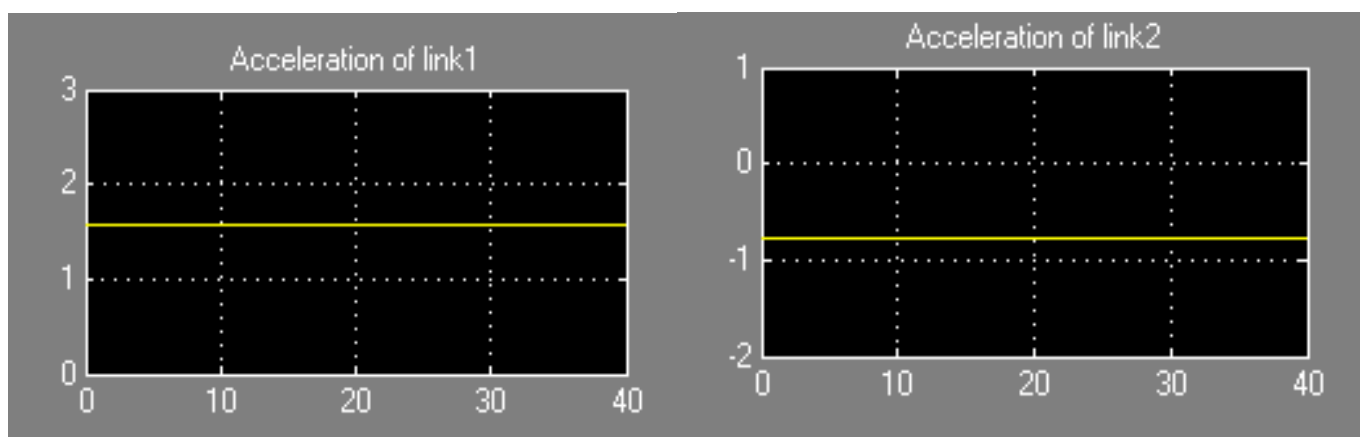

Figure (11): Angular acceleration by derived equations and Simulink model. 


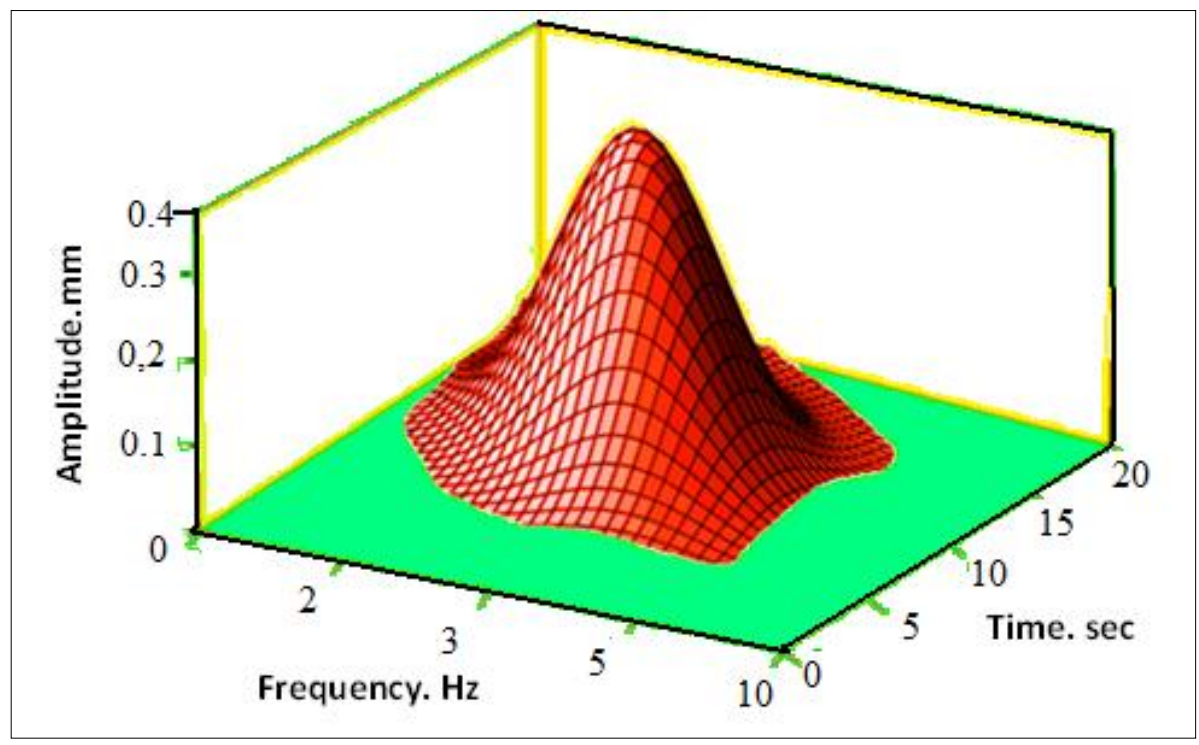

Figure (12): Mode shape of SCARA robot. 


\title{
SCARA التحليل الاهتزازي والحركي لهيكل الرويوت
}

\author{
كاظم محمد عبد \\ طالب حريز عليخ \\ حيار جبار عبد \\ مدرس مساعد \\ مدرس \\ مدرس \\ كلية الهندسة/ جامعة ذي قار \\ كلية الهندسة/ جامعة ذي قار \\ كلية الهندسة/ جامعة ذي قار \\ صلاح مهدي سوادي \\ مدرس مساعد \\ كلية الهندسة/ الجامعة المستتصرية \\ كاظم كريم محسن \\ استاذ مساعد \\ كلية الهندسة/ جامعة ذي قار
}

الخلاصة

يعرض هذا البحث إجراء تحليل لنقييم اهتزاز الروبوتات نوع SCARA. شروط الحركة والتشغيل لمتل هذا النوع من

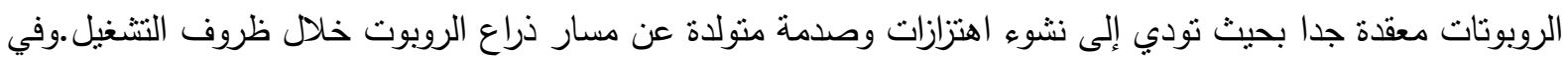

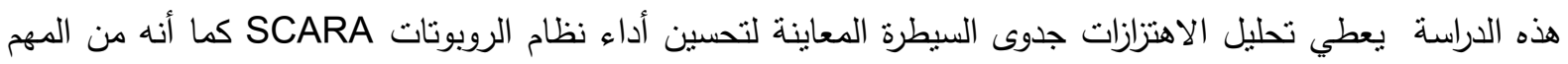

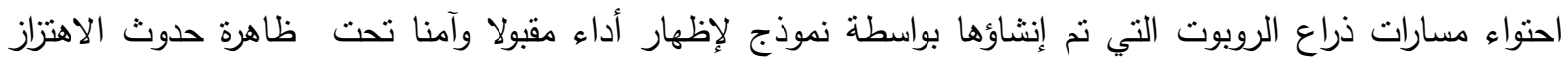

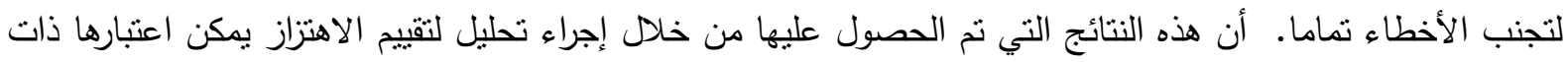

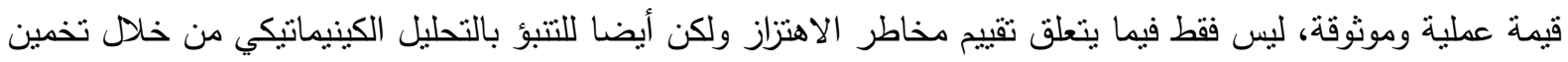

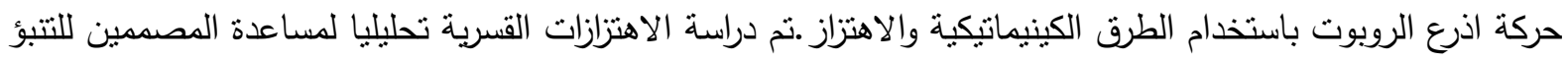

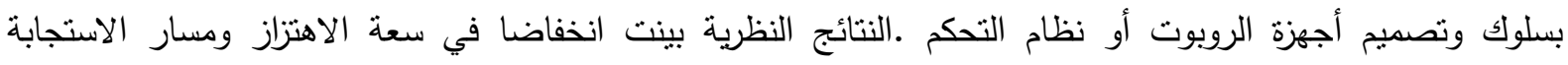
الزمنية. 